- 研究报告・

\title{
胶州湾潮下带大型底栖动物群落的季节变化
}

\author{
杨 梅 ${ }^{1}$ 李新正 ${ }^{1^{*}}$ 徐 勇 ${ }^{1,2}$ 王洪法 ${ }^{1}$ 张宝琳 $^{1}$ \\ 1 (中国科学院海洋研究所海洋生物分类与系统演化实验室, 山东青岛 266071) \\ 2 (中国科学院大学, 北京 100049)
}

\begin{abstract}
摘要: 胶州湾位于山东半岛南岸, 是黄海深入内陆的半封闭天然海湾, 底栖动物种类丰富。本文根据2014年2、5、 8 和 11 月 4 个航次 (冬、春、夏、秋) 的调查资料, 采用优势度指数, 物种多样性指数、丰富度指数、均匀度指数, Bray-Curtis相似性聚类和非参数多维标度排序(NMDS)方法, 分析了胶州湾大型底栖动物群落的季节变化特点。各 航次共采集大型底栖动物 199 种，其中多毛类79种，甲壳动物 47 种，软体动物 40 种，棘皮动物 17 种，其他类群16种。 各季度优势种有变化亦有重叠, 以多毛类为主。2014年度胶州湾大型底栖动物的年平均丰度为 $209.85 \mathrm{ind} . / \mathrm{m}^{2}$, 最 高丰度出现在秋季, 最低出现在春季; 年平均生物量为 $79.22 \mathrm{~g} / \mathrm{m}^{2}$, 最高生物量出现在夏季, 最低出现在春季。物 种多样性指数 $(H)$ 变化范围为2.16-2.86, 物种丰富度指数 $(D)$ 变化范围为2.79-3.72, 物种均匀度指数 $(J)$ 变化范围为 0.58-0.82。聚类分析结果显示, 4 个航次的群落相似性系数均较低, 分布格局存在季节性变化。近年来, 伴随海岸 带开发及人类活动的持续影响, 胶州湾底栖生境的稳定性受到一定的威胁, 建议继续开展长期连续的监测, 探索 有效的综合治理措施，使胶州湾海洋生态系统能够持续健康的发展。
\end{abstract}

关键词: 胶州湾; 大型底栖动物; 生物多样性; 群落结构

\section{Seasonal variations in macrobenthic communities in the subtidal zones of Jiaozhou Bay}

Mei Yang ${ }^{1}$, Xinzheng $\mathrm{Li}^{1 *}$, Yong $\mathrm{Xu}^{1,2}$, Hongfa Wang ${ }^{1}$, Baolin Zhang ${ }^{1}$

1 Department of Marine Organism Taxonomy and Phylogeny, Institute of Oceanology, Chinese Academy of Sciences, Qingdao, Shandong 266071

2 University of Chinese Academy of Sciences, Beijing 100049

\begin{abstract}
Jiaozhou Bay is a semi-enclosed bay at the southern shore of Shandong Peninsula and has abundant macrobenthic species. In present study, the seasonal variation of the macrobenthic community in this bay was analyzed based on data collected from four cruises in February (winter), May (spring), August (summer) and November (autumn) of 2014. A total of 199 macrobenthic species were identified, of which, 79 species were Polychaeta, 47 were Crustacea, 40 were Mollusca, 17 were Echinodermata, and the remaining 16 species belong to other animal groups. The composition of dominant species seasonally varied, however, most of them were species belong to Polychaeta. The average abundance of the macrobenthos from the four cruises was 209.85 ind. $/ \mathrm{m}^{2}$, with the highest abundance found in the autumn cruise and the lowest in the spring cruise. The average biomass from the four cruises was $79.22 \mathrm{~g} / \mathrm{m}^{2}$, with the highest biomass found during the summer cruise and the lowest found during the spring cruise. The Shannon-Wiener index $\left(H^{\prime}\right)$ of the macrobenthic community varied from 2.16 to 2.86 , the species richness index $(D)$ varied from 2.79 to 3.72 and the species evenness index $(J)$ varied from 0.58 to 0.82 . The Bray-Curtis similarity cluster analysis and NMDS ordination analyses indicated that the similarity among macrobenthic community groups was low and the distribution pattern of microbenthic animal groups showed seasonal characteristics. In recent years, with the rapid economic development of coastal zones and the continuous impact of human activities, the stability of the benthonic community in Jiaozhou Bay is threatened, therefore, long-term monitoring is recommended and effective comprehensive management measures need to be explored to result in the healthy
\end{abstract}

收稿日期: 2015-09-30; 接受日期: 2016-01-04

基金项目：中科院先导科技专项(A)“黑潮及其变异对中国近海生态系统的影响”(XDA11020303)和海洋公益性行业科研专项项目(201505004-1)

* 通讯作者 Author for correspondence. E-mail: lixzh@qdio.ac.cn 
and sustainable development of the marine ecosystem in Jiaozhou Bay.

Key words: Jiaozhou Bay; benthic macrofauna; biodiversity; community structure

大型底栖动物多数生活在有机质含量丰富的 沉积物表层, 通过摄食和次级生产等方式影响着整 个海洋生态系统的物质循环和能量流动(李新正等, 2012)。同时, 还兼有种类丰富、分布广泛、回避污 染能力差等特点, 对环境变化较为敏感, 故常用于 监测和评价湖泊、海湾等水环境的污染状况(董鹏 等, 2015)。因此, 探明大型底栖动物的多样性和群 落结构特征对揭示海洋生态环境变化具有重要的 现实意义。

胶州湾 $\left(35^{\circ} 38^{\prime}-36^{\circ} 18^{\prime} \mathrm{N}, 120^{\circ} 04^{\prime}-120^{\circ} 23^{\prime} \mathrm{E}\right)$ 位 于山东半岛南岸, 是黄海深入内陆的半封闭天然海 湾, 属典型的暖温带季风气候(刘瑞玉, 1992; 毕洪 生, 1997; 李新正等, 2001)。其南北长约 $33 \mathrm{~km}$, 东西 宽约 $28 \mathrm{~km}$, 水域面积 $302.91 \mathrm{~km}^{2}$, 滩涂面积 85.12 $\mathrm{km}^{2}$; 大部分海域水深不超过 $10 \mathrm{~m}$, 平均水深 $7 \mathrm{~m}$; 受地理位置、陆地气候和水深等的影响, 水温和盐 度具明显的区域和季节变化(李乃胜, 2006; 钟美明, $2010^{\circledR}$; 马立杰等, 2014)。

胶州湾底栖动物种类丰富、组成复杂, 是我国 最早开展海湾生态学研究的典型区域。1935年, 张 等老一辈科学家便开展了胶州湾的生物区系调 查; 至 20 世纪 50 年代, 中国科学院海洋研究所与前 苏联科学家合作对该区潮间带底栖动物做了详细 研究(古丽娅诺娃和吴宝玲, 1963); 80年代以来, 海 洋科学工作者针对浮游生物和底栖生物等开展了 大量工作(刘瑞玉，1992; 毕洪生和冯卫，1996); 自 1998年起, 李新正等在原有工作的基础上对大型底 栖动物的生物多样性、次级生产力和群落结构等进 行了连续的调查和研究(李新正等, 2001, 2002; 李 宝泉等, 2006; 王金宝等, 2011); 迄今, 作为中国生 态系统研究网络(CERN)成员的胶州湾海洋生态系 统国家野外研究站已发表了大量的研究成果(赵淑 江, 2002; 于海燕等, 2006; 田胜艳等, 2010; 康美 华, $2014^{(2)}$ )。而随着沿岸经济的迅速发展和湾内水产 养殖的不断扩张, 人类活动对胶州湾生态环境的影

(1) 钟美明 (2010) 胶州湾海域生态系统健康评估. 硕士学 位论文, 中国海洋大学, 青岛.

(2) 康美华 (2014) 胶州湾生源要素的时空分布特征研究. 硕士学位论文, 中国海洋大学, 青岛.
响日益加剧, 湾内外的生物种类及群落已发生巨大 变化(齐衍萍等, 2015)。本文根据2014年2、5、8、 11 月共 4 个航次(分别代表冬、春、夏、秋4季)所获 调查资料, 结合历史数据, 分析了胶州湾大型底栖 动物的多样性和群落的季节变化, 目的在于进一步 监测湾内的环境变迁, 为底栖生物资源的合理开发 和可持续利用提供科学依据和资料积累。

\section{1 材料与方法}

\section{1 调查站位和样品采集}

使用中国科学院海洋研究所的“创新”号科考船 开展调查, 在胶州湾内外设置 12 个站位(图1), 于 2014年2月(冬季)、5月(春季)、8月(夏季)和11月(秋 季)各进行 1 个航次。其中 5 月 (春季)航次因风浪过大, 取消了位于湾口的D5站位。定量采样使用 $0.1 \mathrm{~m}^{2}$ 抓 斗采泥器 (大洋-50型) 完成, 每站成功取样 2 次合并 为该站样品。泥样经孔径为 $0.5 \mathrm{~mm}$ 的过滤筛冲洗掉 泥沙, 保留底栖生物样品, 固定保存于 $75 \%$ 的酒精 中, 带回实验室进行种类鉴定、个体计数和称重。

\section{2 数据处理}

\subsection{1 优势度指数}

采用底栖生物优势度指数来判断优势种, 计算 公式如下:

$$
Y=\left(n_{i} / N\right) f_{i}
$$

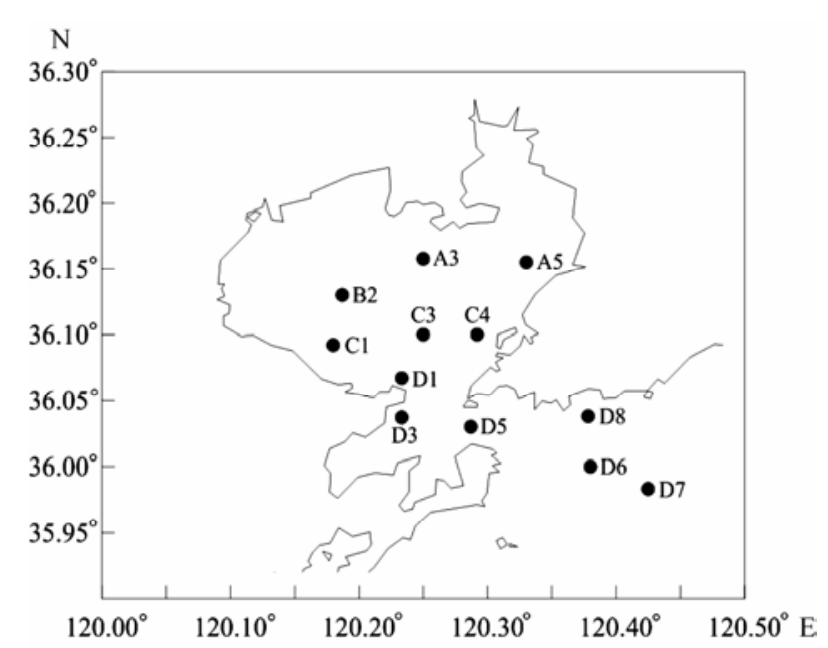

图1 胶州湾调查站位示意图

Fig. 1 The sampling stations of Jiaozhou Bay 
式中, $n_{i}$ 为第 $i$ 种的总个体数; $N$ 为所有站位采集的底 栖生物总个体数; $f_{i}$ 为该物种在各调查站位中出现 的频率(孙儒泳, 1992)。 $Y \geq 0.02$ 时, 即认为该物种为 优势种(徐兆礼和陈亚翟, 1989)。

\subsection{2 群落多样性指数}

群落多样性是衡量群落稳定性的重要尺度, 一 般采用 Shannon-Wiener多样性指数 $\left(H^{\prime}\right)($ Shannon \& Wiener, 1949)、Margalef (1968)物种丰富度指数 $(D)$ 和Pielou (1966)物种均匀度指数 $(J)$ 来综合分析群落 的多样性及影响因素, 各项指数计算公式如下:

$$
\begin{aligned}
& H^{\prime}=-\sum_{i=1}^{S} P_{i} \log _{2} P_{i} \\
& D=(S-1) / \log _{2} N \\
& J=H^{\prime} / \log _{2} S
\end{aligned}
$$

式中, $N$ 为采泥样品中所有种类的总个体数; $S$ 为采 泥样品中的种类总数; $P_{i}$ 为第 $i$ 种的个体数与样品中 总个数的比值 $\left(n_{i} / N\right)$ 。

\subsection{3 群落结构分析}

使用多元统计软件PRIMER 6.0 (Clarke, 1993) 对胶州湾大型底栖动物的群落结构进行分析。为避 免个别数值过高或过低引起的偶然性误差, 我们将 4 个航次的大型底栖动物丰度数据经平方根转化(周 红和张志南, 2003), 然后采用Bray-Curtis相似性等 级聚类(CLUSTER)、非度量多维标度(NMDS)及相 似性百分比(similarity percentage program, SIMPER)
方法, 分析比较群组间的相似性和各航次表征群落 特征的物种。

\section{2 结果}

\section{1 种类组成和优势种}

4 个航次共采集大型底栖动物 199 种(附录1), 其 中环节动物多毛类最多，有79种(占39.70\%); 甲壳 动物次之， 47 种 $(23.62 \%)$; 软体动物 40 种 $(20.10 \%)$; 棘皮动物 17 种 $(8.54 \%)$; 其他类群(腔肠动物、扁形动 物、纽形动物和鱼类等 $) 16$ 种 $(8.04 \%)$ 。冬季航次采 到的物种数最多, 有 99 种, 其中种数最多的站位是 C1 (32种)。其他航次的种数依次为: 秋季 96 种, C4 和D3站采到种数最多(均为 23 种); 夏季 78 种, C4站 采到种数最多(22种); 春季最少, 仅 76 种, 这可能 与风浪过大而放弃了D5站位的采样有关, 其中在 C3站采到种数最多(21种)。4个航次中多毛类的种数 均为最多, 其次为甲壳动物或软体动物 (春季航次), 而棘皮动物和其他类群动物种数均较少(图2)。

4 个航次的优势种见表 1 。其中, 菲律宾蛤仔 (Ruditapes philippinaraum) 为4个季度的共有优势种, 这可能与该物种在湾内有大面积养殖区, 采集到了 较多的人工放养个体有关。秋季的优势种最多达 5 种, 冬季次之(4种), 春季和夏季均各有2种。塞鳃齿 吻沙蚕(Nephtys oligobranchia) 是秋、冬季的优势种, 在春季的 $Y$ 值 $(0.015)$ 也相对较高, 属常见种; 拟特

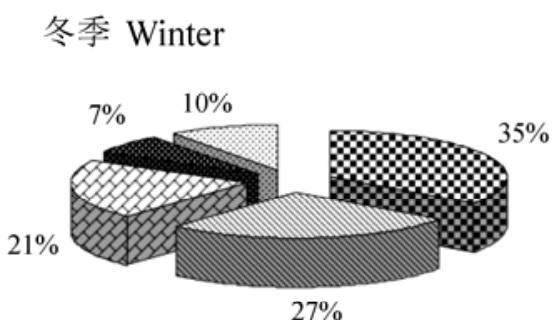

夏季 Summer

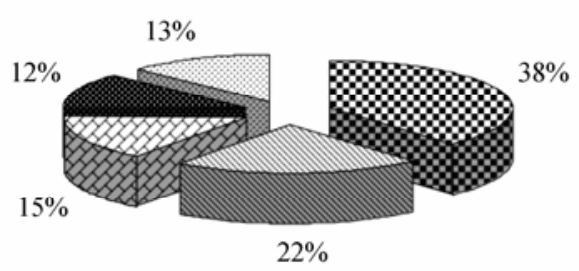

春季 Spring

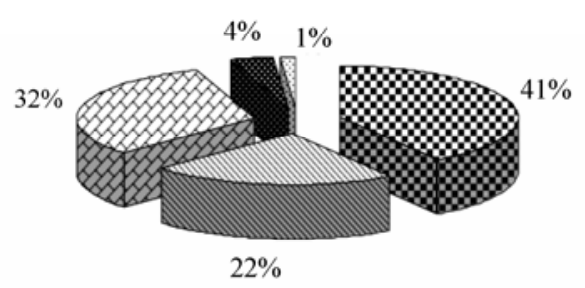

秋季 Autumn

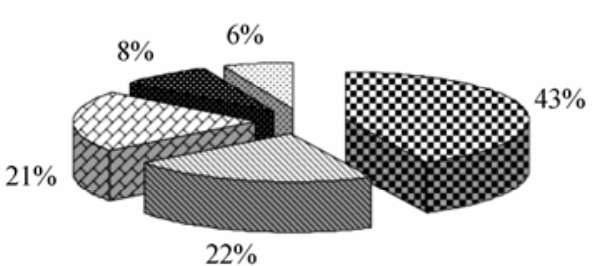

\& 多毛动物 Polychaete 甲壳动物 Crustacea

路 软体动物 Mollusca

棘皮动物 Echinodermata 其他 Others

图2 2014年胶州湾4个季节所获大型底栖动物的物种组成和各类群所占百分比

Fig. 2 Species composition and percentage of benthic macrofauna from four cruises of Jiaozhou Bay in 2014 
表1 2014年胶州湾4个航次优势种和常见种及优势度 $(Y)$

Table 1 Dominant and common species and their dominances $(Y)$ of four cruises in Jiaozhou Bay in 2014

\begin{tabular}{|c|c|c|c|c|}
\hline & $\begin{array}{l}\text { 冬季 } \\
\text { Winter }\end{array}$ & $\begin{array}{l}\text { 春季 } \\
\text { Spring }\end{array}$ & $\begin{array}{l}\text { 夏季 } \\
\text { Summer }\end{array}$ & $\begin{array}{l}\text { 秋季 } \\
\text { Autumn }\end{array}$ \\
\hline 背蚓虫 Notomastus latericeus & 0.021 & & & \\
\hline 菲律宾蛤仔 Ruditapes philippinaraum & 0.033 & 0.127 & 0.143 & 0.046 \\
\hline 寡鳃齿吻沙蚕 Nephtys oligobranchia & 0.027 & 0.015 & & 0.038 \\
\hline 长叶索沙蚕 Lumbrineris longiforlia & 0.027 & & & 0.017 \\
\hline 拟特须虫 Paralacydonia paradoxa & 0.012 & 0.025 & & 0.037 \\
\hline 玉筋鱼 Ammodytes personatus & & & 0.022 & \\
\hline 不倒翁虫 Sternaspis scutata & 0.015 & 0.016 & & 0.039 \\
\hline 深沟毛虫 Sigambra bassi & 0.012 & & & 0.029 \\
\hline 多丝独鳃虫 Tharyx multifilis & 0.016 & & & \\
\hline 日本拟背水風 Paranthura japonica & 0.015 & & & 0.012 \\
\hline 棘刺针参 Protankyra bidentata & & & 0.019 & \\
\hline 雉唇吻沙蚕 Glycera onomichiensis & & & 0.010 & \\
\hline
\end{tabular}

须虫(Paralacydonia paradoxa) 是春、秋季的优势种, 冬季的 $Y$ 值为 0.012 ; 不倒翁虫(Sternaspis scutata) 和 深沟毛虫(Sigambra bassi)也是秋季的优势种, 前者 在冬、春季的 $Y$ 值分别为 0.015 和 0.016 , 接近优势种。 冬季的优势种还有背蚓虫(Notomastus latericeus)和 长叶索沙蚕(Lumbrineris longiforlia); 夏季优势种除 菲律宾蛤仔外, 还包括玉筋鱼(Ammodytes personatus)。另外，多丝独鳃虫(Tharyx multifilis)、日本拟 背水䖝(Paranthura japonica)、棘刺针参(Protankyra bidentata) 和锥唇吻沙䖯 (Glycera onomichiensis) 虽 未成为优势种, 但 $Y$ 值分别在不同季节接近 0.02 , 它 们的生态作用亦不能忽视。总体而言, 胶州湾大型 底栖动物的优势种在不同季节有一定的差异, 但组 成以多毛类为主。

\section{2 丰度与生物量}

\subsection{1 丰度及其季节变化}

胶州湾内的大面积菲律宾蛤仔养殖区会对大 型底栖动物丰度和生物量的统计造成影响, 故而选 择去除该物种。2014年大型底栖动物的平均丰度是 209.85 ind. $/ \mathrm{m}^{2}$ (表 2 ), 各季节从高到低的顺序为: 秋 季 $\left(259.58 \mathrm{ind} . / \mathrm{m}^{2}\right)>$ 冬季 $\left(220.00 \mathrm{ind} . / \mathrm{m}^{2}\right)>$ 夏季 (187.08 ind. $\left./ \mathrm{m}^{2}\right)>$ 春季 $\left(172.73\right.$ ind. $\left./ \mathrm{m}^{2}\right)$ 。

秋季航次中各类群平均丰度由高到低依次为 多毛类、其他类群动物、甲壳动物、软体动物和棘 皮动物; 丰度最高的站位是 C4 (555 ind. $\left./ \mathrm{m}^{2}\right)$, 仅多 毛类就达 455 ind. $/ \mathrm{m}^{2}$, 最低的是D1 (50 ind. $/ \mathrm{m}^{2}$ ) (图 3 )。冬季平均丰度由高到低依次为多毛类、甲壳动
物、软体动物、其他类群动物和棘皮动物; 丰度最 高的站位是 C1 (685 ind. $\left./ \mathrm{m}^{2}\right)$, 最低的是 D7 (25 ind. $\left./ \mathrm{m}^{2}\right)$ 。夏季航次因采集到较多的玉筋鱼, 所以其 他类群的平均丰度最高, 其次为多毛类、棘皮动物、 甲壳动物和软体动物; 丰度最高的站位是D8 (710 ind. $\left./ \mathrm{m}^{2}\right)$, 仅玉筋鱼便达 675 ind. $/ \mathrm{m}^{2}$, 最低的是 $\mathrm{C} 1$ $\left(85 \mathrm{ind} . / \mathrm{m}^{2}\right)$ 。春季平均丰度由高到低的顺序是多毛 类、软体动物、甲壳动物、其他类群和棘皮动物; 丰 度最高的站位是C3 (360 ind. $\left./ \mathrm{m}^{2}\right)$, 最低的是D8 (20 ind. $\left./ \mathrm{m}^{2}\right)$ 。各站位的丰度值在不同航次变化均较大, 高低值的分布明显呈斑块状, 高值区和低值区在不 同季节的位置变化亦较大(图3)。另外, 从年平均丰 度的组成比例来看, 多毛类最高 $\left(109.52 \mathrm{ind} . / \mathrm{m}^{2}\right)$, 占 $52.19 \%$, 在 4 个季节的变化范围为 $60.83-160.83$ ind. $/ \mathrm{m}^{2}$; 棘皮动物最低 $\left(15.41\right.$ ind. $\left./ \mathrm{m}^{2}\right)$, 仅占 $7.34 \%$, 最大平均丰度出现在夏季 $\left(39.58 \mathrm{ind} . / \mathrm{m}^{2}\right)$, 最小在春 季(4.55 ind. $\left./ \mathrm{m}^{2}\right)$ (表2)。

\subsection{2 生物量及其季节变化}

2014年胶州湾调查站位的年平均生物量是 $79.22 \mathrm{~g} / \mathrm{m}^{2}$ (表2), 4 个航次的变化范围为 $39.51-$ $119.85 \mathrm{~g} / \mathrm{m}^{2}$, 波动较大。夏季平均生物量最高 $\left(119.85 \mathrm{~g} / \mathrm{m}^{2}\right)$, 同时因采到较多玉筋鱼, 所以其他 类群占比例最高 $(82.7 \%)$, 其余依次是棘皮动物 $(11.0 \%)$, 软体动物 $(4.7 \%)$, 多毛类 $(1.1 \%)$ 和甲壳动 物 $(0.5 \%)$; 生物量最高的站位是D8 $\left(1,161.57 \mathrm{~g} / \mathrm{m}^{2}\right)$, 最低的是 C4 $\left(4.9 \mathrm{~g} / \mathrm{m}^{2}\right)$, 虽然 $\mathrm{C} 4$ 站采集到的物种数 是D8站的3倍之多, 但多是个体较小的多毛类和甲 壳动物。秋季的平均生物量 $\left(104.32 \mathrm{~g} / \mathrm{m}^{2}\right)$ 居第2位, 不同动物类群所占比例大小依次为: 其他类群 $56.1 \%$, 软体动物 $33.4 \%$, 棘皮动物 $8.4 \%$, 多毛类 $1.3 \%$, 甲壳动物 $0.8 \%$; 生物量最高的站位依然是D 8 $\left(653.23 \mathrm{~g} / \mathrm{m}^{2}\right)$, 最低的是D1 $\left(0.83 \mathrm{~g} / \mathrm{m}^{2}\right)$ 。冬季平均生 物量为 $53.19 \mathrm{~g} / \mathrm{m}^{2}$, 根据其所占比例大小依次为: 软 体动物 $79.2 \%$, 其他类群 $14.1 \%$, 甲壳动物 $3.1 \%$, 多 毛类 $2.2 \%$, 棘皮动物 $1.5 \%$; 生物量最高的站位是 $\mathrm{C} 1$ $\left(489.43 \mathrm{~g} / \mathrm{m}^{2}\right)$, 最低的是D7 $\left(0.30 \mathrm{~g} / \mathrm{m}^{2}\right)$ 。春季的平均 生物量最低 $\left(39.51 \mathrm{~g} / \mathrm{m}^{2}\right)$, 贡献率由高到低依次为: 软体动物 $80.0 \%$, 棘皮动物 $10.8 \%$ 、甲壳动物 $6.3 \%$ 、 多毛类 $2.7 \%$ 、棘皮动物 $0.20 \%$; 其中, A5 (382.39 $\left.\mathrm{g} / \mathrm{m}^{2}\right)$ 是生物量最高的站位, 而D8 $\left(0.01 \mathrm{~g} / \mathrm{m}^{2}\right)$ 仅采 到1种多毛类, 成为全年生物量最低的站位。

排除菲律宾蛤仔造成的偶然性因素后软体动 
表2 2014年胶州湾大型底栖动物主要类群丰度和生物量的季节变化

Table 2 The seasonal abundance (ind. $/ \mathrm{m}^{2}$ ) and biomass $\left(\mathrm{g} / \mathrm{m}^{2}\right)$ of benthic macrofauna main groups in Jiaozhou Bay in 2014

\begin{tabular}{lllllll}
\hline 类群 Group & 项目 Item & 冬季 Winter & 春季 Spring & 夏季 Summer & 秋季 Autumn & 平均 Average \\
\hline 多毛类动物 & 丰度 Abundance & 114.58 & 101.82 & 60.83 & 160.83 & 109.52 \\
Polychaeta & 生物量 Biomass & 1.18 & 1.09 & 1.29 & 1.32 & 1.22 \\
甲壳动物 & 丰度 Abundance & 48.75 & 15.45 & 11.67 & 28.33 & 26.05 \\
Crustacea & 生物量 Biomass & 1.67 & 2.47 & 0.57 & 0.86 & 1.39 \\
软体动物 & 丰度 Abundance & 32.50 & 41.82 & 6.25 & 26.25 & 26.71 \\
Mollusca & 生物量 Biomass & 42.14 & 31.62 & 5.66 & 34.89 & 28.58 \\
棘皮动物 & 丰度 Abundance & 7.50 & 4.55 & 39.58 & 10.00 & 15.41 \\
Echinodermata & 生物量 Biomass & 0.80 & 4.25 & 13.16 & 8.77 & 6.75 \\
其他类群 & 丰度 Abundance & 16.67 & 9.09 & 68.75 & 34.17 & 32.17 \\
Others & 生物量 Biomass & 7.49 & 0.08 & 99.17 & 58.48 & 41.31 \\
总计 & 丰度 Abundance & 220.00 & 172.73 & 187.08 & 259.58 & 209.85 \\
Total & 生物量 Biomass & 53.19 & 39.51 & 119.85 & 104.32 & 79.22 \\
\hline
\end{tabular}
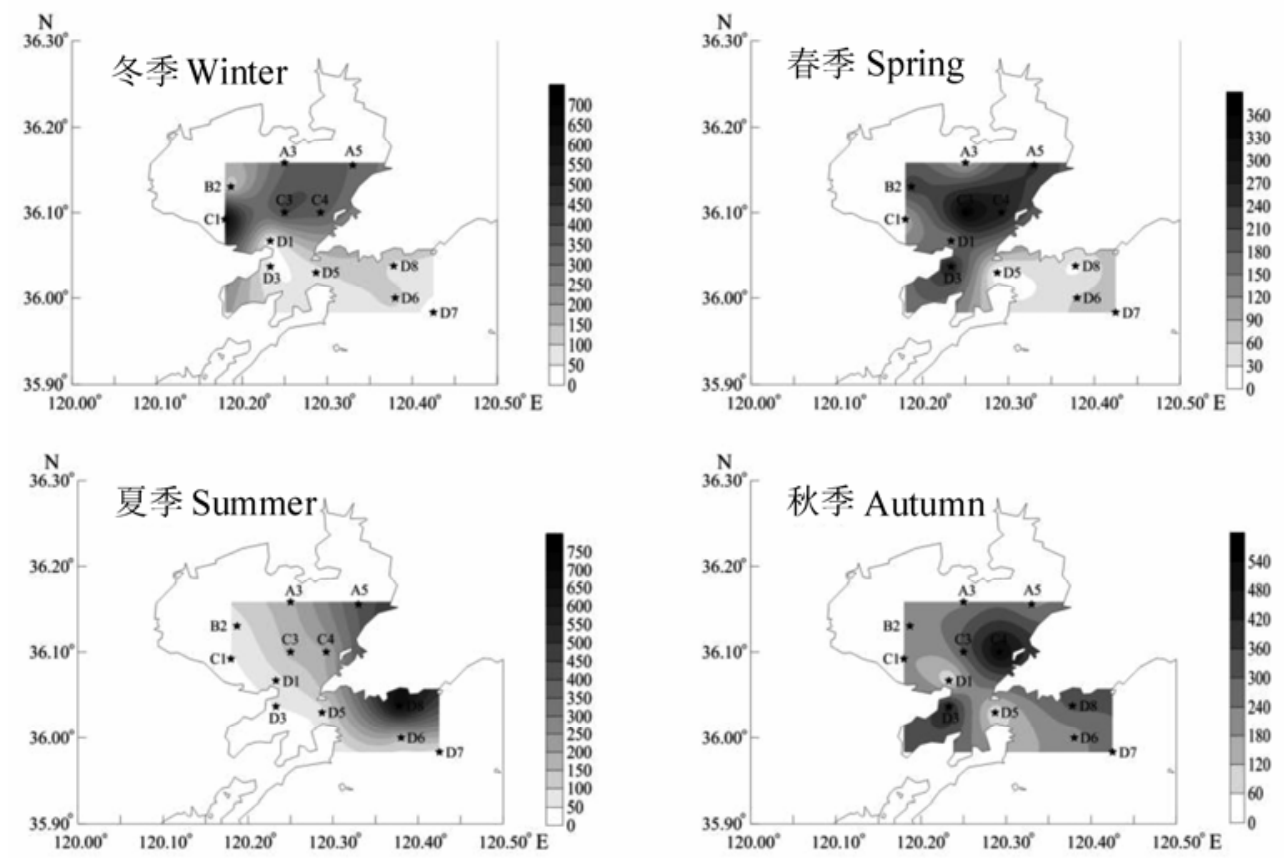

图32014年胶州湾4个航次大型底栖动物丰度分布

Fig. 3 Abundance (ind. $/ \mathrm{m}^{2}$ ) distribution of benthic macrofauna from four cruises of Jiaozhou Bay in 2014

物的生物量在各季节组成中依然占据较大优势; 而 在种类组成和丰度中占优势的多毛类，因个体普遍 较小导致其对生物量贡献偏小。从生物量的站位分 布来看(图4), 胶州湾海域内高低值分布不连续, 呈 斑块状，高值区主要位于湾内及近岸水域。

\section{3 群落多样性指数}

由表 3 可知, 各站位的物种多样性指数 $\left(H^{\prime}\right)$ 在不 同季节无明显变化规律, 冬、秋季的平均物种多样 性指数最高 (2.86), 夏季次之 (2.34), 春季最低 (2.16); 其全年最高值出现在冬季A5站位(4.07)。物
种丰富度指数 $(D)$ 在季节间的平均值差异亦不甚明 显, 从高到低依次为: 冬季(3.72)>秋季(3.48) > 夏季 (2.88)>春季 $(2.79)$; 全年最高的 $D$ 值出现在冬季 $\mathrm{C} 1$ 站位 $(6.30)$ 。物种均匀度指数 $(J)$ 各季节的平均值依 次为：冬季 $(0.82)>$ 秋季 $(0.77)>$ 夏季 $(0.70)>$ 春季 $(0.58)$; 全年最高的 $J$ 值出现在冬季的 D1 和 D3 站位, 均是 1.00 。

\section{4 群落结构分析}

对胶州湾 4 个航次的大型底栖动物进行群落 CLUSTER聚类和NMDS排序分析(图5)，结果表明， 

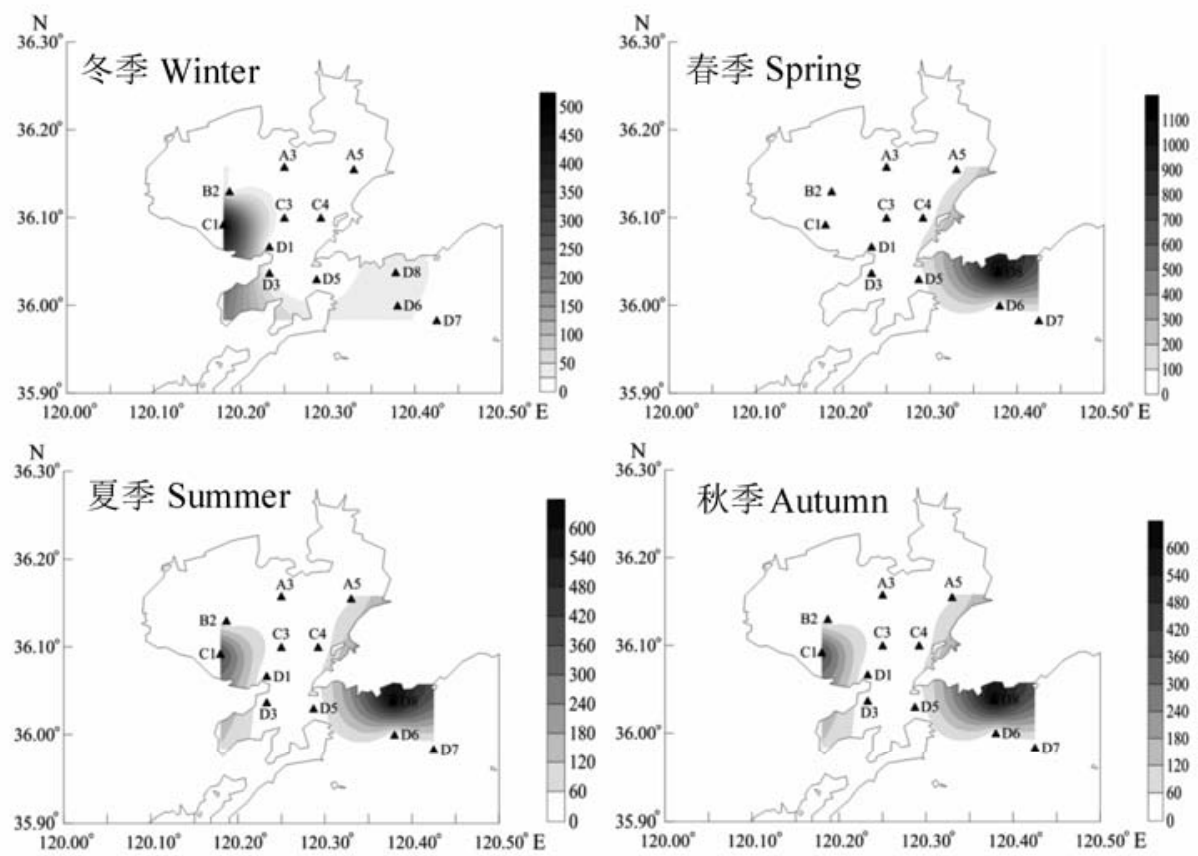

图4 2014年胶州湾4个航次大型底栖动物生物量分布

Fig. 4 Biomass $\left(\mathrm{g} / \mathrm{m}^{2}\right)$ distribution of benthic macrofauna from four cruises of Jiaozhou Bay in 2014

表3 2014年胶州湾4个航次大型底栖动物群落多样性指数

Table 3 Shannon-Wiener index $\left(H^{\prime}\right)$, Margalef richness index $(D)$ and Pielou evenness index $(J)$ of benthic macrofauna in four cruises of Jiaozhou Bay in 2014

\begin{tabular}{|c|c|c|c|c|c|c|c|c|c|c|c|c|}
\hline \multirow{2}{*}{$\begin{array}{l}\text { 站位 } \\
\text { Station }\end{array}$} & \multicolumn{3}{|c|}{ 冬季 Winter } & \multicolumn{3}{|c|}{ 春季 Spring } & \multicolumn{3}{|c|}{ 夏季 Summer } & \multicolumn{3}{|c|}{ 秋季 Autumn } \\
\hline & $\overline{H^{\prime}}$ & $D$ & $J$ & $\overline{H^{\prime}}$ & $D$ & $J$ & $\overline{H^{\prime}}$ & $D$ & $J$ & $H^{\prime}$ & $D$ & $J$ \\
\hline$\overline{\mathrm{A} 3}$ & 2.80 & 3.01 & 0.72 & 0.70 & 1.88 & 0.20 & 0.55 & 2.80 & 0.13 & 3.29 & 4.11 & 0.81 \\
\hline A5 & 4.07 & 5.43 & 0.89 & 4.00 & 5.14 & 0.91 & 0.54 & 1.14 & 0.21 & 3.42 & 3.94 & 0.85 \\
\hline B2 & 1.44 & 3.16 & 0.36 & 1.34 & 3.08 & 0.32 & 3.05 & 3.56 & 0.85 & 0.95 & 1.96 & 0.27 \\
\hline $\mathrm{C} 1$ & 3.68 & 6.30 & 0.73 & 3.17 & 3.29 & 0.92 & 2.48 & 2.53 & 0.83 & 4.06 & 5.26 & 0.94 \\
\hline $\mathrm{C} 3$ & 3.88 & 5.64 & 0.83 & 3.63 & 4.68 & 0.83 & 3.89 & 4.86 & 0.93 & 3.32 & 4.59 & 0.78 \\
\hline $\mathrm{C} 4$ & 3.03 & 4.43 & 0.70 & 2.92 & 3.96 & 0.71 & 4.05 & 5.69 & 0.91 & 3.93 & 4.67 & 0.87 \\
\hline D1 & 2.59 & 2.79 & 1.00 & 1.13 & 1.20 & 0.49 & 2.56 & 2.82 & 0.81 & 2.17 & 1.74 & 0.94 \\
\hline D3 & 3.00 & 3.37 & 1.00 & 2.53 & 3.23 & 0.66 & 2.37 & 2.17 & 0.92 & 3.46 & 4.89 & 0.76 \\
\hline D5 & 2.22 & 2.53 & 0.74 & - & - & - & 2.71 & 2.59 & 0.90 & 2.45 & 2.42 & 0.87 \\
\hline D6 & 3.66 & 4.21 & 0.96 & 3.24 & 3.51 & 0.98 & 2.20 & 1.44 & 0.85 & 3.20 & 3.50 & 0.84 \\
\hline D7 & 2.98 & 3.11 & 0.90 & 3.24 & 3.46 & 0.94 & 3.24 & 3.69 & 0.94 & 3.61 & 4.43 & 0.85 \\
\hline D8 & 0.97 & 0.62 & 0.97 & 0.00 & 0.00 & - & 0.41 & 1.21 & 0.15 & 0.50 & 0.24 & 0.50 \\
\hline $\begin{array}{l}\text { 平均值 Aver- } \\
\text { age }\end{array}$ & 2.86 & 3.72 & 0.82 & 2.16 & 2.79 & 0.58 & 2.34 & 2.88 & 0.70 & 2.86 & 3.48 & 0.77 \\
\hline
\end{tabular}

一表示此站未取样。

- showed that the station without sampling.

群组间的相似性系数较低(在10-60\%之间), 北部的 站位能够形成较大的群组, 但各群组站位分布较分 散且存在季节性差异。4个航次的压力系数(stress) 均小于 0.2 , 说明可以正确解释样本间的相似关系。

冬季分为 5 个群组, 群组I包括 5 个站位: A5、
C1、C3、C4和D6, 平均相似性 $40.1 \%$ ，表征种是长 叶索沙毛(贡献率 $14.6 \%$ ) 和寡鳃齿吻沙蚕(贡献率 $14.6 \%)$; 群组II由A3和B2组成，平均相似性 $49.2 \%$, 表征种是菲律宾蛤仔(贡献率 $48.7 \%$ )和葟鳃齿吻沙 䖯(贡献率7.88\%); 群组III有D3、D5和D7共3个站 


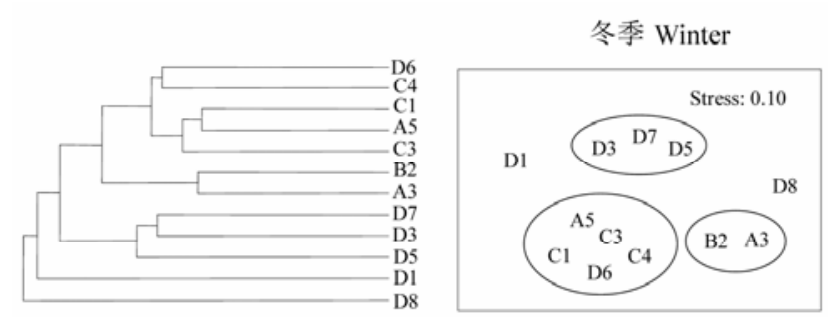

夏季 Summer
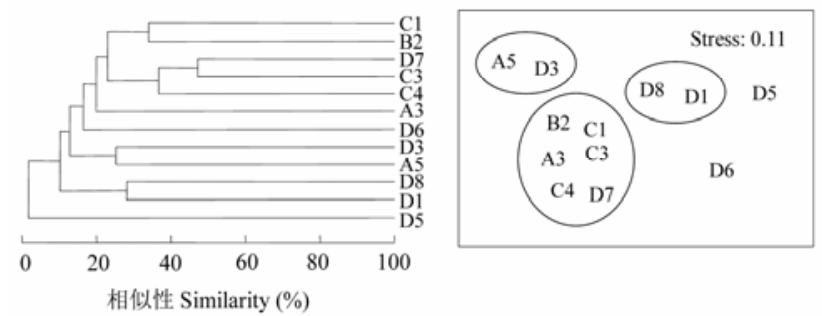
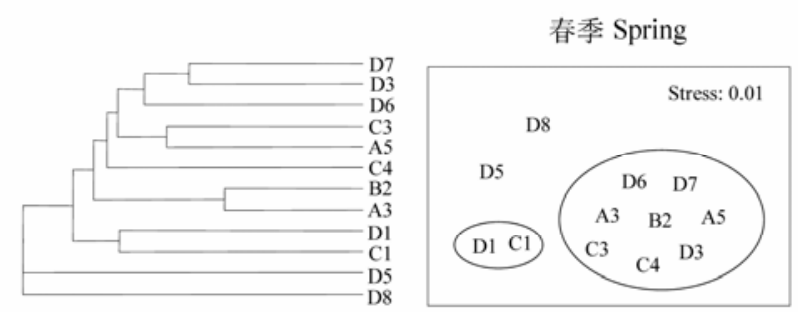

秋季 Autumn
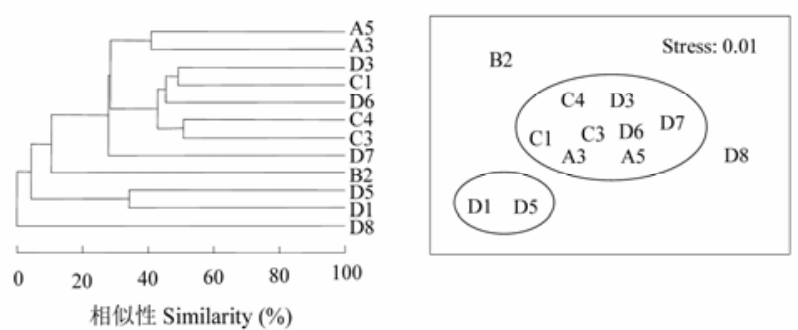

图5 2014年胶州湾各季大型底栖动物群落结构聚类分析和非参数多维标度排序(NMDS)

Fig. 5 Analysis of cluster and NMDS ordination of macrobenthic community of Jiaozhou Bay in seasons of 2014

位, 平均相似性 $34.7 \%$, 表征种为拟特须虫(贡献率 $50.0 \%$ ); 群组 $\mathrm{IV}$ 和 $\mathrm{V}$ 都只包含 1 个站位, 分别是 $\mathrm{D} 1$ 和D 8 。

春季在 $20 \%$ 的相似性水平上可划分为 4 个群组, 群组I站位较多，包括A3、A5、B2、C3、C4、D3、 D6 和D7, 平均相似性 $27.2 \%$, 表征种为拟特须虫(贡 献率 $15.2 \%$ )和寡鳃齿吻沙蚕(贡献率 $13.8 \%$ ); 群组II 包含 $\mathrm{C} 1$ 和D1, 平均相似性 $28.4 \%$; 群组III和IV分别 是 $\mathrm{D} 5$ 和 $\mathrm{D} 8$ 。

夏季可以被划分为 5 个群组, 群组I包含 A3、 $\mathrm{B} 2 、 \mathrm{C} 1 、 \mathrm{C} 3 、 \mathrm{C} 4$ 和D7, 平均相似性 $26.2 \%$, 贡献率 较高的表征种是雉唇吻沙䖯 $(15.7 \%)$ 、寡鳃齿吻沙䖯 $(13.0 \%)$ 和不倒翁虫 $(12.6 \%)$; 群组 II包含 $\mathrm{A} 5$ 和 $\mathrm{D} 3$, 平均相似性 $25.3 \%$, 表征种是棘刺针参 (贡献率 $63.4 \%$ ); 群组 III包含 D1 和 D8, 平均相似性 $28.1 \%$, 表征种是玉筋鱼 (贡献率 41.4\%) 和青岛文昌鱼 (Branchiostoma belcheri tsingtauense)( 贡献 率 29.3\%); D5 和D6分属于群组IV和V。

秋季在 $20 \%$ 的相似性水平上被划分为 4 个群组, 群组I包括 8 个站位: A3、A5、C1、C3、C4、D3、 D6和D7, 平均相似性 $34.6 \%$, 表征种有拟特须虫(贡 献率 $18.3 \%$ )、寡鳃齿吻沙蚕(贡献率 $17.2 \%$ )、不倒翁 虫 (贡献率 $17.2 \%$ ) 和深沟毛虫 (贡献率 $14.6 \%$ ); 群组 II由 D1 和 D5 组成, 平均相似性 $34.3 \%$, 表征种为东 方缝栖蛤(Hiatella orientalis); B2和D8站则各自成
为一个群组。

\section{3 讨论}

\section{1 群落种类组成和优势种变化}

胶州湾地理位置优越, 底栖生物种类丰富, 但 随着 20 世纪 80 年代末沿岸经济的迅速发展和菲律 宾蛤仔的过度捕捞, 湾内底栖生境受到了严重破 坏, 生物种类数锐减。至 90 年代末期为改善胶州湾 生态环境, 禁止各种形式的底拖网作业, 并自2001 年开始实行夏季休渔制度, 海域环境得以改善, 大 型底栖动物的种数逐步恢复(王金宝等, 2011)。本次 调查共采集底栖动物 199 种, 其中多毛类种数最多, 其次为甲壳动物或软体动物, 棘皮动物和其他类群 动物种数较少。王洪法等(2011)在2000-2009年的10 年间, 采集到的种数介于159-206之间, 可见每年 采集到的种数未呈现一定的规律, 种数差别属正常 的年际波动。与以往工作相比(李新正等, 2001; 于 海燕等, 2006; 王洪法等, 2011; 王金宝等, 2011), 2014年各主要类群在总种数中所占比例基本保持 稳定, 未发生大的变化。此外, 随着分类学研究的 不断深入, 之前的一些不确定种得到了准确的鉴定 (An \& Li, 2005; 张宝琳等, 2007; Zhou et al, 2009; 韩庆喜和李新正, 2010)。据统计, 与1998-2001年相 比，2005-2009年的种类组成已增加了百余种(王金 宝等, 2011)。 
20 世纪 80 年代初期的调查中, 优势种种类在不 同动物类群中基本呈均衡分布, 如甲壳动物中的豆 形短眼蟹(Xenophthalmus pinnotheroides)、线毛细足 蟹(Raphidopus ciliatus)、日本游泳水䖝(Natatolana japonica) 和塞切尔泥钩虾 (Eriopisella sechellensis); 软体动物中的秀丽波纹蛤(Raetellops pulchella) 和脆 壳理蛤(Theora fragilis); 棘皮动物中的日本倍棘蛇 尾 (Amphioplus japonicus) 和细雕刻勒海胆 (Temnopleurus toreumaticus)等。而伴随胶州湾底栖 生境的不断变迁和人类活动的持续影响, 上述物种 已从湾内大量消失, 相应的底栖动物群落结构亦发 生了较大变化(毕洪生等, 2001)。本研究中出现的优 势种以多毛类为主(背蚓虫、寡鳃齿吻沙蚕、长叶索 沙蚕、拟特须虫、不倒翁虫和深沟毛虫), 另外有些 物种在某些站位会有较大丰度, 但在其他站位丰度 极低或不出现, 达不到优势种的 $Y$ 值标准。例如, 冬 季的日本拟背水䖝 $(Y$ 值 0.015$)$ 和夏季的棘刺针参 $(Y$ 值 0.019)(表1), 前者在冬季航次 $\mathrm{C} 4$ 站位的丰度是 100 ind. $/ \mathrm{m}^{2}$, 但在 $\mathrm{A} 5 、 \mathrm{C} 1 、 \mathrm{D} 1$ 和D5站位丰度较低, 后者在夏季航次A5站位丰度高达 $380 \mathrm{ind} . / \mathrm{m}^{2}$, 而在 $\mathrm{A} 3$ 和D3站位丰度很低。

\section{2 丰度和生物量的变化}

一定时期内, 特定海域中生物丰度和生物量的 变化可反映其群落的变化, 进而可推断环境的变 化。在计入菲律宾蛤仔的情况下, 1998-1999年胶州 湾大型底栖动物的平均丰度是 $381.73 \mathrm{ind} . / \mathrm{m}^{2}$, 2000-2004年是304.60 ind. $/ \mathrm{m}^{2}$ (李新正等, 2005), 2005-2009年是378.55 ind. $/ \mathrm{m}^{2}$ (不计入则为 280.88 ind. $/ \mathrm{m}^{2}$ ) (王金宝等, 2011); 根据我们的调查数据, 2014年的总平均丰度 (不计菲律宾蛤仔) 是 209.85 ind. $/ \mathrm{m}^{2}$, 包含菲律宾蛤仔则为 354.60 ind. $/ \mathrm{m}^{2}$, 可见 近年来湾内大型底栖动物的丰度是基本稳定的。

秋冬季节的平均丰度高于春夏季节, 这可能是 由于秋冬温度较低, 为个体较小的多毛类提供了更 多的生存机会, 而春夏季捕食动物活跃, 控制了小 个体生物的种群数量。另外, 各主要动物类群的平 均丰度亦呈季节性变化(表2)。例如, 多毛类的平均 丰度在秋季最高 (160.83 ind. $\left./ \mathrm{m}^{2}\right)$, 冬季 (114.58 ind. $\left./ \mathrm{m}^{2}\right)$ 和春季 $\left(101.82 \mathrm{ind} . / \mathrm{m}^{2}\right)$ 次之, 夏季最低 $\left(60.83\right.$ ind. $\left./ \mathrm{m}^{2}\right)$; 在 $2005-2009$ 年的数据中, 最高平 均丰度则出现在冬季 $\left(176.48 \mathrm{ind} . / \mathrm{m}^{2}\right)$, 春秋次之, 夏季亦最低(119.28 ind. $/ \mathrm{m}^{2}$ ) (王金宝等, 2011)。甲壳
动物、软体动物、棘皮动物和其他类群的平均丰度 在不同季节的变化也较显著。

去除菲律宾蛤仔后胶州湾大型底栖动物的年 平均生物量为 $79.22 \mathrm{~g} / \mathrm{m}^{2}$, 计入则为 $350.31 \mathrm{~g} / \mathrm{m}^{2}$, 可 见其对群落生物量的贡献巨大。相比王金宝等 (2011) 2005-2009年统计的平均生物量变化范围 24.77- $41.18 \mathrm{~g} / \mathrm{m}^{2}$ 有所提高。在历年平均丰度基本持 平的情况下, 生物量增加, 说明近年来胶州湾的底 栖生境相对稳定, 个体的生长期较长, 能够长得更 大, 体重得以增加。各主要动物类群的平均生物量 无明显的季节变化规律(表2)。多毛类在不同季节的 平均生物量变化不大 $\left(1.09-1.32 \mathrm{~g} / \mathrm{m}^{2}\right)$, 且均低于 2005-2009年各季节的平均生物量 (2.14-3.63 g/ $\left.\mathrm{m}^{2}\right)$ (王金宝等, 2011); 甲壳动物在春季平均生物量最高 $\left(2.47 \mathrm{~g} / \mathrm{m}^{2}\right)$, 夏季最低 $\left(0.57 \mathrm{~g} / \mathrm{m}^{2}\right)$; 软体动物的平均 生物量在春、秋、冬季的变化不大, 但夏季明显偏低; 棘皮动物在夏季平均生物量最高 $\left(13.16 \mathrm{~g} / \mathrm{m}^{2}\right)$, 冬季 最低 $\left(0.80 \mathrm{~g} / \mathrm{m}^{2}\right)$; 其他类群包括纽虫、鱼类等, 一般 个体较大, 在夏秋季节对平均生物量的贡献最大。

从丰度和生物量的空间分布来看(图3,4), 两者 的高值区和低值区在 4 个季节并不一致, 而研究表 明底质、温度、盐度和人为扰动等因素是进一步导 致大型底栖动物的丰度和生物量呈斑块状分布的 重要原因(毕洪生, 1997; 田胜艳等, 2010; 刘晓收 等, 2014)。

\section{3 群落多样性}

胶州湾大型底栖动物群落的物种多样性指数 $\left(H^{\prime}\right)$ 、丰富度指数 $(D)$ 和均匀度指数 $(J)$ 的空间分布均 差异较大。目前普遍认为泥沙等混合型沉积环境的 多样性高于泥或砂等匀质的沉积环境, 湾内各站多 属粉砂-粘土或粘土-粉砂混合型底质且水深较浅, 有机质含量高, 物种多样性较高; 而湾口外多为粗 砂-砾石等匀质底质且水深流急, 物种种类单一(毕 洪生, 1997; 田胜艳等, 2010; 王金宝等, 2011)。例如 湾外靠近青岛市区岸边的D8站位, 底质为有机质 含量低的疏松粗砂, 仅青岛文昌鱼得到发展而使群 落多样性指数均偏低。当然, 除空间差异外, 群落 多样性在不同季节亦有一定变化。秋冬季节的多样 性指数略高于春夏季, 可能是由于春夏季湾内的人 工养殖使某些优势种类如菲律宾蛤仔大量繁殖, 导 致底栖生物群落失衡, 种类趋向单一、结构趋向简 单, 多样性指数降低。 
另外, 物种多样性指数 $\left(H^{\prime}\right)$ 不但被普遍用来描 述群落的生态学特征, 也常用于环境质量的评价。 蔡立哲等(2002)建议将多样性指数污染评价范围分 为 5 级: 无底栖动物为严重污染; $H^{\prime}$ 值小于 1 , 为重 度污染; $H^{\prime}$ 值介于 $1-2$ 之间, 为中度污染; $H^{\prime}$ 值在2-3 之间, 轻度污染; $H^{\prime}$ 值大于 3 , 为清洁。亦有研究表 明, 多样性指数评价污染程度的值与研究区域的沉 积环境有关, 不同生境选择多样性指数的分值有所 不同(Wetsbegrtsbegr et al, 1997)。李新正等(2001)曾 指出, 胶州湾底栖动物的物种多样性指数平均值介 于3.33-3.50之间，但 2014年的 $H^{\prime}$ 年平均值是 2.56, 属轻度污染状况，与隋吉星等(2010)对胶州湾中部 海域调查得出的结论一致, 说明频繁的人为活动还 是在一定程度上影响了胶州湾的底栖生境, 致使底 栖动物多样性降低。

\section{4 群落结构}

早在 20 世纪 90 年代初, 刘瑞玉(1992)便将湾内 底栖生物划分为6个群落: (1)文昌鱼 (Branchiostoma belcheri)群落; (2)海蛹(Ophelina aulogaser)-扇栉虫 (Ampharete sp.)群落; (3)细雕刻勒海胆-日本倍棘蛇 尾群落; (4)菲律宾蛤仔-日本游泳水闽群落; (5)棘刺 针参-胡桃蛤 (Leioncula sp.) 群落; (6)勒特蛤 (Raeta pulchella)-菲律宾蛤仔群落。而随着时间的推移, 其 群落结构和表征种都发生了很大变化: 聚类分析 中，12个站位在不同季节的群组格局变化较大, 只 有位于湾中央的 $\mathrm{C} 3$ 和 $\mathrm{C} 4$ 始终处于同一群组, 相似 度较高; 北部的站位因水深较浅, 靠近河口, 有机 营养物质极丰富, 次级生产力高于海湾的南部区域 而能够在不同季节形成较大的群组(王金宝等, 2011); 位于湾口及湾外的D1、D5、D6和D8等受粗 砂底质及海流的影响各自成为一个群组。影响群落 结构的因素主要包括生物和非生物因素(水深、海 流、粒度、温度和盐度等) (毕洪生, 1997; 刘晓收等, 2014)。于海燕等(2006)研究指出, 胶州湾底质特征 是控制底栖生物分布和丰度的重要因子; 田胜艳等 (2010)将胶州湾大型底栖动物的丰度和生物量分别 与环境因子(水深、沉积物粒径组成及有机质质量分 数、含水量、叶绿素质量比)进行相关性分析, 结果 显示丰度与所测的各项环境变量均表现出显著的 相关性, 生物量则复杂些, 在不同季节与不同环境 变量呈现显著相关; 亦有分析表明影响胶州湾及其 邻近海域鱼类群落结构的主要环境因子为水温、盐
度和 $\mathrm{pH}$, 其次是底质类型(翟璐等, 2014)。在今后的 调查中, 应着重加强对环境因子的监测和分析，以 期更好地阐明其与大型底栖动物群落结构变化的 作用机制。

海洋中的底栖动物能够通过营养关系在水层 底栖耦合过程中将生态系统连接为一个整体, 其种 类组成、群落结构等生态特点能够反映人类活动对 海洋生态造成的影响(李新正等, 2012)。例如, 头索 动物青岛文昌鱼对栖息地的海水、底质等环境条件 要求较高, 仅分布于胶州湾有机质含量低且为纯净 粗砂的个别站位，在2000-2009年的10年间有 6 个年 度的优势度 $Y$ 值介于 $0.013-0.042$ 之间, 被认为是胶 州湾的常见种(王洪法等, 2011)。然而在2014年度的 调查中发现其种群数量锐减, 年平均 $Y$ 值仅为 0.0009 , 充分说明胶州湾海域环境质量有所降低。 一直以来, 胶州湾顶部广阔的潮滩都是海岸带围填 海开发的重点, 海湾面积的持续减少, 直接导致其 自净能力降低, 使生态系统的健康受到威胁(李颖虹, 2010; 雷宁等, 2013); 同时, 陆源污水的大量排放、 海水养殖过程中投放的过量饵料等都会使海水富营 养化, 加剧赤潮、水母暴发等海洋灾害。虽然胶州湾 的环境已从 20 世纪 90 年代严重污染的状态逐渐恢复, 但物种多样性指数 $\left(H^{\prime}\right)$ 的年平均值不足 3.00 , 亦从侧 面说明目前仍存在一定程度的污染。对此, 建议进一 步提高胶州湾近岸海域环境管理力度, 继续开展长 期连续的监测, 探索有效的综合治理措施, 使胶州 湾海洋生态系统得以持续健康的发展。

致谢: 王金宝、董栋、寇琦、隋吉星、甘志涁、龚 琳、王跃云等参加了本研究的野外考察、实验室样 品处理和鉴定等工作, 并在论文写作过程中提出了 良好建议; 中国科学院海洋生物标本馆管理员为本 研究的样品处理给予了大力支持和协助, 在此一并 致以衰心的感谢。

\section{参考文献}

An JM, Li XZ (2005) First record of the family Spengeliidae (Hemichordata: Enteropneusta) from Chinese waters, with description of a new species. Journal of Natural History, 39, 1995-2004.

Bi HS (1997) The environmental influences on macrobenthos in Jiaozhou Bay. Marine Science, 21(1), 37-40. (in Chinese) [毕洪生 (1997) 胶州湾环境对底栖生物的影响. 海洋科 学, 21(1), 37-40.] 
Bi HS, Feng W (1996) The diversity of macrobenthos in Jiaozhou Bay. Marine Science, 20(6), 58-62. (in Chinese with English abstract) [毕洪生, 冯卫 (1996) 胶州湾底栖 生物多样性初探. 海洋科学, 20(6), 58-62.]

Bi HS, Sun S, Sun DY (2001) Changes of macrobenthic communities in Jiaozhou Bay. Oceanologia et Limnologia Sinica, 32, 132-138. (in Chinese with English abstract) [毕 洪生, 孙松, 孙道远 (2001) 胶州湾大型底栖生物群落结 构的变化. 海洋与湖沼, 32, 132-138.]

Cai LZ, Ma L, Gao Y, Zheng TL, Lin P (2002) Analysis on assessing criterion for polluted situation using species diversity index of marine macrofauna. Journal of Xiamen University, 41, 641-646. (in Chinese with English abstract) [蔡 立哲, 马丽, 高阳, 郑天凌, 林鹏 (2002) 海洋底栖动物 多样性指数污染程度评价标准的分析. 厦门大学学报, 41, 641-646.]

Clarke KR (1993) Non-parametric multivariate analyses of changes in community structure. Australian Journal of Ecology, 18, 117-143.

Dong P, Zhang HB, Ye XS, Xu R, Zhou J (2015) Community structure and biodiversity characteristics of macrobenthos in the middle of Xiangshan Bay. Journal of Shanghai Ocean University, 24, 430-440. (in Chinese with English abstract) [董鹏, 张海波, 叶仙森, 徐㓞, 周进 (2015) 象山港中部 海域大型底栖动物群落组成及多样性特征. 上海海洋大 学学报, 24, 430-440.]

Gurjanova PV, Wu BL (1963) Benthic community from Jiaozhou Bay. Studia Marina Sinica, (3), 51-61. (in Chinese) [古丽娅诺娃, 吴宝铃 (1963) 胶州湾底栖生物群落. 海洋科学集刊, (3), 51-61.]

Han QX, Li XZ (2010) Records of the Crangonidae (Crustacea, Decapoda, Caridea) species from the Yellow Sea and Bohai Sea. Acta Zootaxonomica Sinica, 35, 227-239. (in Chinese with English abstract) [韩庆喜, 李新正 (2010) 黄、渤海褐 虾科(甲壳动物亚门, 软甲纲, 十足目)记述. 动物分类学 报, 35, 227-239.]

Lei N, Hu XY, Zhou XH (2013) Evolution process and ecological effect analysis of reclamation in Jiaozhou Bay. Marine Environmental Science, 32, 506-509. (in Chinese with English abstract) [雷宁, 胡小颖, 周兴华 (2013) 胶州湾 围填海的演进过程及其生态环境影响分析. 海洋环境科 学, 32, 506-509.]

Li BQ, Li XZ, Wang HF, Zhang BL (2006) Species diversity of macrobenthic mollusk fauna in Jiaozhou Bay, Shandong. Biodiversity Science, 14, 136-144. (in Chinese with English abstract) [李宝泉, 李新正, 王洪法, 张宝琳 (2006) 胶州 湾大型底栖软体动物物种多样性研究. 生物多样性, 14 , 136-144.]

Li NS (2006) Natural Environment and Geological Evolution of Jiaozhou Bay. China Ocean Press, Beijing. (in Chinese) [李乃胜 (2006) 胶州湾自然环境与底质变化. 海洋出版 社, 北京.]

Li XZ, Yu HY, Wang YQ, Shuai LM, Zhang BL, Liu RY
(2001) Study on species diversity of macrobenthic fauna in Jiaozhou Bay. Biodiversity Science, 9, 80-84. (in Chinese with English abstract) [李新正, 于海燕, 王永强, 帅莲梅, 张宝琳, 刘瑞玉 (2001) 胶州湾大型底栖动物的物种多 样性现状. 生物多样性, 9, 80-84.]

Li XZ, Yu HY, Wang YQ, Shuai LM, Zhang BL, Li XH (2002) Study on the quantitative dynamics of macrobenthos in Jiaozhou Bay. Studia Marina Sinica, 44, 66-73. (in Chinese with English abstract) [李新正, 于海燕, 王永强, 帅莲梅, 张宝琳, 李笑红 (2002) 胶州湾大型底栖动物数量动态 的研究. 海洋科学集刊, 44, 66-73.]

Li XZ, Wang HF, Zhang BL (2005) The secondary production of macrobenthos in Jiaozhou Bay, Shandong. Oceanologia et Limnologia Sinica, 36, 527-533. (in Chinese with English abstract) [李新正, 王洪法, 张宝琳 (2005) 胶州湾大型底 栖动物次级生产力初探. 海洋与湖沼, 36, 527-533.]

Li XZ, Wang HF, Zhang BL, Ma L, Zhang L (2012) Advance of the study on the macrobenthos from the Yellow Sea and East China Sea. Sustainable Development, (2), 80-102. (in Chinese with English abstract) [李新正, 王洪法, 张宝琳, 马林, 张立 (2012) 黄海和东海大型底栖生物生态学研 究进展. 可持续发展, (2), 80-102.]

Li YH (2010) The Study of Jiaozhou Bay Ecosystem Dynamic Change. PhD dissertation, Institute of Oceanology, Chinese Academy of Sciences, Qingdao. (in Chinese with English abstract) [李颖虹 (2010) 胶州湾生态系统动态变化研究. 博士学位论文, 中国科学院海洋研究所, 青岛.]

Liu RY (1992) Ecology and Living Resources of Jiaozhou Bay. Science Press, Beijing. (in Chinese) [刘瑞玉 (1992) 胶州 湾生态学和生物资源. 科学出版社, 北京.]

Liu XS, Fan Y, Shi SJ, Hua E, Zhang ZN (2014) Studies on the species composition and community structure of macrofauna in the Bohai Sea, China. Acta Oceanologica Sinica, 36(12), 53-66. (in Chinese with English abstract) [刘晓收, 范颖, 史书杰, 华尔, 张志南 (2014) 渤海大型底栖动物种类组 成与群落结构研究. 海洋学报, 36(12), 53-66.]

Ma LJ, Yang XG, Qi YL, Liu YX, Zhang JZ (2014) Oceanic area change and contribution factor of Jiaozhou Bay. Scientia Geographica Sinica, 34, 365-369. (in Chinese with English abstract) [马立杰, 杨䂀光, 祁雅莉, 刘艳霞, 张金枝 (2014) 胶州湾海域面积变化及原因探讨. 地理科学, 34, 365-369.]

Margalef R (1968) Perspective in Ecological Theory. University of Chicago Press, Chicago.

Pielou EC (1966) The use of information theory in the study of ecological succession. Journal of Theoretical Biology,10, 370-383.

Qi YP, Yang XF, Song WP, Yin WH (2015) Ecological problems and countermeasures of Jiaozhou Bay. Journal of Guangxi Academy of Sciences, 31(2), 94-96. (in Chinese with English abstract) [齐衍萍, 杨晓飞, 宋文鹏, 尹维翰 (2015) 胶州湾海域生态问题及解决对策. 广西科学院学 报, 31(2), 94-96.] 
Shannon CE, Wiener W (1949) The Mathematical Theory of Communication. University of Illinois Press, Urbana.

Sui JX, Yu ZS, Qu FY, Liu WX (2010) Preliminary ecological study of the macrobenthos in the middle part of the Jiaozhou Bay. Marine Science, 34(5), 1-6. (in Chinese with English abstract) [隋吉星, 于子山, 曲方圆, 刘卫霞 (2010) 胶州 湾中部海域大型底栖生物生态学初步研究. 海洋科学, 34(5), 1-6.]

Sun RY (1992) Principle of Animal Ecology, 2nd edn. Beijing Normal University Press, Beijing. (in Chinese) [孙儒泳 (1992) 动物生态学原理(第二版). 北京师范大学出版社, 北京.]

Tian SY, Zhang WL, Yu ZS, Zhang ZN (2010) Abundance, biomass and secondary production of macrobenthos in the Jiaozhou Bay, China. Marine Science, 34(6), 81-87. (in Chinese with English abstract) [田胜艳, 张文亮, 于子山, 张志南 (2010) 胶州湾大型底栖动物的丰度、生物量和生 产量研究. 海洋科学, 34(6), 81-87.]

Wang HF, Li XZ, Wang JB (2011) Macrobenthic composition and its changes in the Jiaozhou Bay during 2000-2009. Oceanologia et Limnologia Sinica, 42, 738-752. (in Chinese with English abstract) [王洪法, 李新正, 王金宝 (2011) 2000-2009年胶州湾大型底栖动物的种类组成及变化. 海 洋与湖沼, 42, 738-752.]

Wang JB, Li XZ, Wang HF, Zhang BL (2011) Ecological study on the macrobenthos in the Jiaozhou Bay in 2005-2009. Oceanologia et Limnologia Sinica, 42, 728-737. (in Chinese with English abstract) [王金宝, 李新正, 王洪法, 张宝琳 (2011) 2005-2009年胶州湾大型底栖动物生态学研究. 海 洋与湖沼, 42, 728-737.]

Wetsbegrtsbegr SB, Rnaasinhge JA, Dauer DM, Schaffner LC, Diaz RJ, Frithsen JB (1997) An estuarine benthic index of biotic integrity (B-IBI) for Chesapeake Bay. Estuaries, 20, 149-158.

Xu ZL, Chen YQ (1989) Aggregated intensity of dominant species of zooplankton in autumn in the East China Sea and Yellow Sea. Chinese Journal of Ecology, 8(4), 13-15. (in Chinese with English abstract) [徐兆礼, 陈亚篗 (1989) 东
黄海秋季浮游动物优势种聚集强度与鲐鲐渔场的关系. 生态学杂志, 8(4), 13-15.]

Yu HY, Li XZ, Li BQ, Wang JB, Wang HF (2006) The species diversity of macrobenthic fauna in Jiaozhou Bay. Acta Ecologica Sinica, 26, 416-422. (in Chinese with English abstract) [于海燕, 李新正, 李宝泉, 王金宝, 王洪法 (2006) 胶州湾大型底栖动物生物多样性现状. 生态学报, 26 , 416-422.]

Zhai L, Han DY, Fu DJ, Zhang CL, Xue Y (2014) Fish community structure and the relationship with environmental factors in Jiaozhou Bay and adjacent waters. Journal of Fishery Sciences of China, 21, 810-821. (in Chinese with English abstract) [翟璐, 韩东燕, 傅道军, 张崇良, 薛芗 (2014) 胶州湾及其邻近海域鱼类群落结构及与环境因子 的关系. 中国水产科学, 21, 810-821.]

Zhang BL, Wang HF, Zhang WY, Li BQ, Li XZ (2007) Species and distribution of Enteropneusta from Jiaozhou. Marine Science, 31(2), 65-67. (in Chinese with English abstract) [张宝琳, 王洪法, 张文勇, 李宝泉, 李新正 (2007) 胶州湾肠鳃类种类与分布. 海洋科学, 31(2), 65-67.]

Zhao SJ (2002) Long-term Changes of Main Ecological Factors of the Jiaozhou Bay Ecosystem. PhD dissertation, Institute of Oceanology, Chinese Academy of Sciences, Qingdao. (in Chinese with English abstract) [赵淑江 (2002) 胶州湾生 态系统主要生态因子的长期变化. 博士学位论文, 中国 科学院海洋研究所, 青岛.]

Zhou H, Zhang ZN (2003) Rationale of the multivariate statistical software PRIMER and its application in benthic community ecology. Journal of Ocean University of Qingdao, 33(1), 58-64. (in Chinese with English abstract) [周红, 张 志南 (2003) 大型多元统计软件PRIMER的方法原理及其 在底栖群落生态学中的应用. 青岛海洋大学学报, 33(1), 58-64.]

Zhou J, Ji W, Li XZ (2009) A new species of Scolelepis (Polychaeta: Spionidae) from sandy beaches in China, with a review of Chinese Scolelepis species. Zootaxa, 6(2236), $37-49$.

\section{附录 Supplementary Material}

附录12014年胶州湾大型底栖动物物种名录

Appendix 1 Macrobenthic species list recorded in Jiaozhou Bay in 2014

http://www.biodiversity-science.net/fileup/PDF/2015264-1.pdf 
杨梅, 李新正, 徐勇, 王洪法, 张宝琳. 胶州湾潮下带大型底栖动物群落的季节变化. 生物多样性, 2016, 24 (7): 822-830.

http://www.biodiversity-science.net/CN/10.17520/biods.2015264

附录 12014 年胶州湾大型底栖动物物种名录

Appendix 1 Macrobenthic species list recorded in Jiaozhou Bay in 2014

\begin{tabular}{|c|c|c|c|}
\hline 科中文名 & 科拉丁名 & 种中文名 & 种拉丁名 \\
\hline \multicolumn{4}{|c|}{ 腔肠动物门 Coelenterata } \\
\hline 钟螅科 & Campanulariidae & 中国根茎螅 & Rhizocaulus chinensis \\
\hline 棒海鰓科 & Veretillidae & 海仙人掌 & Cavernularia sp. \\
\hline 沙箸海鳃科 & Virgulariidae & 沙箸 & Virgularia sp. \\
\hline \multicolumn{4}{|c|}{ 扁形动物门 Platyhelminthes } \\
\hline 背浴虫科 & Notoplanidae & 薄背浴虫 & Notocomplana humilis \\
\hline \multicolumn{4}{|c|}{ 纽形动物门 Nemertinea } \\
\hline 合孔科 & Amphiporidae & 斑两用孔纽虫 & Amphiporus punctatulus \\
\hline \multicolumn{4}{|c|}{ 环节动物门 Annelida } \\
\hline 帚毛虫科 & Sabellariidae & 雉毛似帚毛虫 & Lygdamis giardi \\
\hline 缨鳃虫科 & Sabellidae & 领管缨虫 & Chone collaris \\
\hline 缨鰓虫科 & Sabellidae & 温哥华真旋虫 & Eudistylia vancouveri \\
\hline 缨鰓虫科 & Sabellidae & 巨刺缨虫 & Potamilla myriops \\
\hline 缨鰓虫科 & Sabellidae & 缨鳃虫 & Sabella pencillus \\
\hline 扇毛虫科 & Flabelligeridae & 线毛肾扇虫 & Brada villosa \\
\hline 扇毛虫科 & Flabelligeridae & 孟加拉海扇虫 & Pherusa bengalensis \\
\hline 丝鳃虫科 & Cirratulidae & 刚鳃虫 & Chaetozone sefosa \\
\hline 丝鰓虫科 & Cirratulidae & 细丝鳃虫 & Cirratulus filiformis \\
\hline 丝鰓虫科 & Cirratulidae & 须鳃虫 & Cirriformia tentaculata \\
\hline 丝鰓虫科 & Cirratulidae & 多丝独毛虫 & Tharyx multifilis \\
\hline 双栉虫科 & Ampharetidae & 扁鳃扇栉虫 & Amphicteis scophrobranchiata \\
\hline 双栉虫科 & Ampharetidae & 纳氏沟栉虫 & Anobothrus nataliae \\
\hline 双栉虫科 & Ampharetidae & 毛鳃尖栉虫 & Lysippe trichobranchia sp. nov. \\
\hline 双栉虫科 & Ampharetidae & 米列虫 & Melinna cristata \\
\hline 笔帽虫科 & Pectinaridae & 连膜帽虫 & Lagis bocki \\
\hline 笔帽虫科 & Pectinaridae & 那不勒斯膜帽虫 & Lagis neapolitana \\
\hline 蛰龙介科 & Terebellidae & 扁蛰虫 & Loimia medusa \\
\hline 蛰龙介科 & Terebellidae & 树蛰虫 & Pista cristata \\
\hline 毛鳃虫科 & Trichobranchidae & 双毛鳃虫 & Trichobranchus bibranchiatus \\
\hline 海稚虫科 & Spionidae & 雉稚虫 & Aonides oxycephala \\
\hline 海稚虫科 & Spionidae & 后稚虫 & Laonice cirrata \\
\hline 海稚虫科 & Spionidae & 日本细稚齿虫 & Prionospio japonica \\
\hline 杂毛虫科 & Poecilochaetidae & 蛇杂毛虫 & Poecilochaetus serpens \\
\hline 吻沙蚕科 & Glyceridae & 雉唇吻沙蚕 & Glycera onomichiensis \\
\hline 吻沙蚕科 & Glyceridae & 长突半足沙蚕 & Hemipodus yenourensis \\
\hline 角吻沙蚕科 & Goniadidae & 寡节甘吻沙蚕 & Glycinde gurjanovae \\
\hline 角吻沙蚕科 & Goniadidae & 日本角吻沙寔 & Goniada japonica \\
\hline 多鳞虫科 & Polynoidae & 渤海格鳞虫 & Gattyana pohaiensis \\
\hline 多鳞虫科 & Polynoidae & 亚洲哈鳞虫 & Harmothoë asiatica \\
\hline
\end{tabular}


杨梅, 李新正, 徐勇, 王洪法, 张宝琳. 胶州湾潮下带大型底栖动物群落的季节变化. 生物多样性, 2016, 24 (7): 822-830.

http://www.biodiversity-science.net/CN/10.17520/biods.2015264

\begin{tabular}{|c|c|c|c|}
\hline 多鳞虫科 & Polynoidae & 覆瓦哈鳞虫 & Harmothoë imbricata \\
\hline 多鳞虫科 & Polynoidae & 有齿背鳞虫 & Lepidonotus dentatus \\
\hline 多鳞虫科 & Polynoidae & 软背鳞虫 & Lepidonotus helotypus \\
\hline 锡鳞虫科 & Sigalionidae & 黄海刺梳鳞虫 & Ehlersileanira incisa hwanghaiensis \\
\hline 锡鳞虫科 & Sigalionidae & 日本强鳞虫 & Sthenolepis japonica \\
\hline 特须虫科 & Lacydonidae & 拟特须虫 & Paralacydonia paradoxa \\
\hline 叶须虫科 & Phyllodocidae & 中华半突虫 & Phyllodoce chinensis \\
\hline 叶须虫科 & Phyllodocidae & 格棱兰半突虫 & Phyllodoce groenlandica \\
\hline 叶须虫科 & Phyllodocidae & 叶须虫 & Phyllodoce laminosa \\
\hline 叶须虫科 & Phyllodocidae & 梭须半突虫 & Phyllodoce madeirensis \\
\hline 叶须虫科 & Phyllodocidae & 乳突半突虫 & Phyllodoce papillosa \\
\hline 齿吻沙蚌科 & Nephtyidae & 中华内卷齿蚕 & Aglaophamus sinensis \\
\hline 齿吻沙蚕科 & Nephtyidae & 无病齿吻沙蚕 & Inermonephtys inermis \\
\hline 齿吻沙蚕科 & Nephtyidae & 囊叶齿吻沙蚕 & Nephtys caeca \\
\hline 齿吻沙蚕科 & Nephtyidae & 寡鳃齿吻沙蚕 & Nephtys oligobranchia \\
\hline 沙蚌科 & Nereididae & 羽须鰓沙䖯 & Dendronereis pinnaticirris \\
\hline 沙蚕科 & Nereididae & 日本刺沙䖯 & Neanthes japonica \\
\hline 沙蚕科 & Nereididae & 长须沙蚕 & Nereis longior \\
\hline 沙蚕科 & Nereididae & 游沙蚕 & Nereis pelagica \\
\hline 沙蚕科 & Nereididae & 背褶沙蚕 & Tambalagamia fauveli \\
\hline 海女虫科 & Hesionidae & 双小健足虫 & Micropodarke dubia \\
\hline 海女虫科 & Hesionidae & 狭细蛇潜虫 & Ophiodromus angutifrons \\
\hline 白毛虫科 & Pilargidae & 巴氏钩毛虫 & Sigambra bassi \\
\hline 白毛虫科 & Pilargidae & 花冈钩毛虫 & Sigambra hanaokai \\
\hline 白毛虫科 & Pilargidae & 长须钩毛虫 & Sigambra tentaculata \\
\hline 裂虫科 & Syllidae & 额刺裂虫 & Ehlersia cornuta \\
\hline 仙虫科 & Amphinomidae & 含糊拟刺虫 & Linopherus ambigua \\
\hline 仙虫科 & Amphinomidae & 边鳃拟刺虫 & Linopherus paucibranchiata \\
\hline 索沙蚕科 & Lumbrineridae & 双唇索沙蚕 & Lumbrineris cruzensis \\
\hline 索沙蚕科 & Lumbrineridae & 异足索沙䖯 & Lumbrineris heteropoda \\
\hline 索沙蚕科 & Lumbrineridae & 短叶索沙蚕 & Lumbrineris latreilli \\
\hline 索沙蚕科 & Lumbrineridae & 长叶索沙蚌 & Lumbrineris longiforlia \\
\hline 索沙蚕科 & Lumbrineridae & 四索沙蚕 & Lumbrineris tetraura \\
\hline 矶沙蚕科 & Eunicidae & 矶沙蚕 & Eunice aphroditois \\
\hline 矶沙蚕科 & Eunicidae & 扁平岩虫 & Marphysa depressa \\
\hline 竹节虫科 & Maldanidae & 真节虫 & Euclymene oerstedi \\
\hline 竹节虫科 & Maldanidae & 缩头竹节虫 & Maldane sarsi \\
\hline 竹节虫科 & Maldanidae & 拟节虫 & Praxillella praeterrrifssa \\
\hline 小头虫科 & Capitellidae & 小头虫 & Capitella capitata \\
\hline 小头虫科 & Capitellidae & 厚鳃蚕 & Dasybranchus caducus \\
\hline 小头虫科 & Capitellidae & 丝异须虫 & Heteromastus filiformis \\
\hline 小头虫科 & Capitellidae & 中蚓虫 & Mediomastus californiensis \\
\hline 小头虫科 & Capitellidae & 背毛背蚓虫 & Notomastus aberans \\
\hline 小头虫科 & Capitellidae & 背蚓虫 & Notomastus latericeus \\
\hline
\end{tabular}


杨梅, 李新正, 徐勇, 王洪法, 张宝琳. 胶州湾潮下带大型底栖动物群落的季节变化. 生物多样性, 2016, 24 (7): 822-830.

http://www.biodiversity-science.net/CN/10.17520/biods.2015264

\begin{tabular}{|c|c|c|c|}
\hline 海蛹科 & Opheliidae & 角海蛹 & Ophelina acuminate \\
\hline 雉头虫科 & Orbiniidae & 膜囊尖雉虫 & Scoloplos marsupialis \\
\hline 异毛虫科 & Paraonidae & 独指虫 & Aricidea fragilis \\
\hline 单指虫科 & Cossuridae & 拟单指虫 & Cossurella dimorpha \\
\hline 不倒翁虫科 & Sternaspidae & 不倒翁虫 & Sternaspis scutata \\
\hline \multicolumn{4}{|c|}{ 软体动物门 Mollusca } \\
\hline 锉石鳖科 & Ischnochitonidae & 朝鲜鳞带石鳖 & Lepidozona coreanica \\
\hline 顶管角贝科 & Episiphonidae & 胶州湾顶管角贝 & Episiphon kaochowwanense \\
\hline 马蹄螺科 & Trochidae & 单一丽口螺 & Calliostoma unicum \\
\hline 丽口螺科 & Calliostomatidae & 口马丽口螺 & Calliostoma koma \\
\hline 帆螺科 & Calyptraeidae & 扁平管帽螺 & Siphopatella walshi \\
\hline 玉螺科 & Naticidae & 扁玉螺 & Neverita didyma \\
\hline 梯螺科 & Epitoniidae & 习氏阿玛螺 & Amaea thielei \\
\hline 光螺科 & Eulimidae & 马丽亚瓷光螺 & Eulima maria \\
\hline 核螺科 & Columbellidae & 丽小笔螺 & Mitrella bella \\
\hline 织纹螺科 & Nassariidae & 秀丽织纹螺 & Nassarius festivus \\
\hline 织纹螺科 & Nassariidae & 半褶织纹螺 & Nassarius semiplicatus \\
\hline 织纹螺科 & Nassariidae & 红带织纹螺 & Nassarius succinctus \\
\hline 塔螺科 & Turridae & 杰氏裁判螺 & Inquisitor jeffreysii \\
\hline 露齿螺科 & Ringiculidae & 耳口露齿螺 & Ringicula doliaris \\
\hline 囊螺科 & Restusidae & 尖卷螺 & Rhizorus radiola \\
\hline 三叉螺科 & Cylichnidae & 圆筒原盒螺 & Eocylichna braunsi \\
\hline 壳蛞蝓科 & Philinidae & 银白齿缘壳蛞蝓 & Yokoyamaia argentata \\
\hline 胡桃蛤科 & Nuculidae & 豆形胡桃蛤 & Nucula faba \\
\hline 蚶科 & Arcidae & 内褶拟蚶 & Arcopsis interplicata \\
\hline 蚶科 & Arcidae & 对称拟蚶 & Arcopsis symmetrica \\
\hline 蚶科 & Arcidae & 毛蚶 & Scapharca kagoshimensis \\
\hline 贻贝科 & Mytilidae & 凸壳肌蛤 & Musculus senhousia \\
\hline 锉蛤科 & Limidae & 函馆雪锉蛤 & Limaria hakodatensis \\
\hline 牡蛎科 & Ostreidae & 长牡蚛 & Crassostrea gigas \\
\hline 牡蚛科 & Ostreidae & 猫爪牡蚛 & Talonostrea talonata \\
\hline 蹄蛤科 & Ungulinidae & 津知圆蛤 & Cycladicama tsuchi \\
\hline 蛤蜊科 & Mactridae & 秀丽波纹蛤 & Raetellops pulchella \\
\hline 樱蛤科 & Tellinidae & 圆楔樱蛤 & Cadella narutoensis \\
\hline 樱蛤科 & Tellinidae & 彩虹明樱蛤 & Moerella iridescens \\
\hline 樱蛤科 & Tellinidae & 江户明樱蛤 & Moerella jedoensis \\
\hline 双带蛤科 & Semelidae & 内肋蛤 & Endopleura lubrica \\
\hline 双带蛤科 & Semelidae & 微小海螂 & Leptomya minuta \\
\hline 双带蛤科 & Semelidae & 理蛤 & Theora lata \\
\hline 竹蛏科 & Solenidae & 小刀蛏 & Cultellus attenuatus \\
\hline 竹蛏科 & Solenidae & 短竹蛏 & Solen dunkerianus \\
\hline 刀蛏科 & Cultellidae & 小刀蛏 & Cultellus attenuatus \\
\hline 帘蛤科 & Veneridae & 凸镜蛤 & Dosinia derupta \\
\hline 窝蛤科 & Veneridae & 菲律宾蛤仔 & Ruditapes philippinarum \\
\hline
\end{tabular}


杨梅, 李新正, 徐勇, 王洪法, 张宝琳. 胶州湾潮下带大型底栖动物群落的季节变化. 生物多样性, 2016, 24 (7): 822-830.

http://www.biodiversity-science.net/CN/10.17520/biods.2015264

\begin{tabular}{|c|c|c|c|}
\hline 缝栖蛤科 & Hiatellidae & 东方缝栖蛤 & Hiatella orientalis \\
\hline 色雷西蛤科 & Thracidae & 金星蝶铰蛤 & Trigonothracia jinxingae \\
\hline \multicolumn{4}{|c|}{ 节肢动物门 Arthropoda } \\
\hline 藤壶科 & Balanidae & 糊斑藤壶 & Balanus cirratus \\
\hline 虾蛄科 & Squillidae & 口虾蛄 & Oratosquilla oratoria \\
\hline 双眼钩虾科 & Ampeliscidae & 博氏双眼钩虾 & Ampelisca bocki \\
\hline 双眼钩虾科 & Ampeliscidae & 短角双眼钩虾 & Ampelisca brevicornis \\
\hline 双眼钩虾科 & Ampeliscidae & 轮双眼钩虾 & Ampelisca cyclops \\
\hline 双眼钩虾科 & Ampeliscidae & 美原双眼钩虾 & Ampelisca miharaensis \\
\hline 双眼钩虾科 & Ampeliscidae & 中型双眼钩虾 & Ampelisca miops \\
\hline 双眼钩虾科 & Ampeliscidae & 三崎双眼钩虾 & Ampelisca misakiensis \\
\hline 双眼钩虾科 & Ampeliscidae & 日本沙钩虾 & Byblis japonicus \\
\hline 蜾贏蜚科 & Corophiidae & 日本拟钩虾 & Gammaropsis japonica \\
\hline 蜾贏蜚科 & Corophiidae & 大蜾贏蜚 & Sinocorophium major \\
\hline 蜾贏蜚科 & Corophiidae & 中华蜾贏蜚 & Sinocorophium sinence \\
\hline 利尔钩虾科 & Lijeborgiidae & 弯指铲钩虾 & Listriella curvidactyla \\
\hline 马尔他钩虾科 & Melitidae & 头角泥钩虾 & Eriopisella propagatio \\
\hline 马尔他钩虾科 & Melitidae & 塞切尔泥钩虾 & Eriopisella sechellensis \\
\hline 马尔他钩虾科 & Melitidae & 长指马尔他钩虾 & Melita longidactyla \\
\hline 合眼钩虾科 & Oedicerotidae & 胶州湾壳颚钩虾 & Chitinomandibulum jiaozhouwanensis \\
\hline 涟虫科 & Bodotriidae & 舌突圆涟虫 & Cyclaspis linguiloba \\
\hline 涟虫科 & Bodotriidae & 宽甲古涟虫 & Eocuma lata \\
\hline 涟虫科 & Bodotriidae & 细长涟虫 & Iphinoe tenera \\
\hline 尖额涟虫科 & Leuconidae & 二齿半尖额涟虫 & Hemileucon bidentatus \\
\hline 拟背水虫科 & Paranthuridae & 日本拟背水闽 & Paranthura japonica \\
\hline 浪漂水闽科 & Cirolanidae & 日本游泳水闽 & Natatolana japonensis \\
\hline 对虾科 & Penaeidae & 细巧仿对虾 & Parapenaeopsis tenella \\
\hline 对虾科 & Penaeidae & 鹰爪虾 & Trachysalambria curvirostris \\
\hline 鼓虾科 & Alpheidae & 短脊鼓虾 & Alpheus brevicristatus \\
\hline 鼓虾科 & Alpheidae & 鲜明鼓虾 & Alpheus distinguendus \\
\hline 鼓虾科 & Alpheidae & 日本鼓虾 & Alpheus japonicus \\
\hline 鼓虾科 & Alpheidae & 日本角鼓虾 & Athanas japonicus \\
\hline 藻虾科 & Hippolytidae & 中华安乐虾 & Eualus sinensis \\
\hline 藻虾科 & Hippolytidae & 直额七腕虾 & Heptacarpus rectirostris \\
\hline 藻虾科 & Hippolytidae & 病背深额虾 & Latreutes planirostris \\
\hline 长眼虾科 & Ogyrididae & 东方长眼虾 & Ogyrides orientalis \\
\hline 玻璃虾科 & Pasiphaeidae & 尖尾细螯虾 & Leptochela aculeocaudata \\
\hline 玻璃虾科 & Pasiphaeidae & 细螯虾 & Leptochela gracilis \\
\hline 美人虾科 & Callianassidae & 美人虾 & Callianassa sp. \\
\hline 蝼蛄虾科 & Upogebiidae & 伍氏奥蝼蛄虾 & Upogebia wuhsienweni \\
\hline 瓷蟹科 & Porcellanidae & 锯额豆瓷蟹 & Pisidia serratifrons \\
\hline 瓷蟹科 & Porcellanidae & 线毛细足蟹 & Raphidopus ciliatus \\
\hline 关公蟹科 & Dorippidae & 日本拟平家蟹 & Heikeopsis japonica \\
\hline 长脚蟹科 & Goneplacidae & 隆线强蟹 & Eucrate crenata \\
\hline
\end{tabular}


杨梅, 李新正, 徐勇, 王洪法, 张宝琳. 胶州湾潮下带大型底栖动物群落的季节变化. 生物多样性, 2016, 24 (7): 822-830.

http://www.biodiversity-science.net/CN/10.17520/biods.2015264

$\begin{array}{llll}\text { 六足蟹科 } & \text { Hexapodidae } & \text { 颗粒仿六足蟹 } & \text { Hexapinus granuliferus } \\ \text { 菱蟹科 } & \text { Parthenopidae } & \text { 强壮武装紧握菱蟹 } & \text { Enoplolambrus validus } \\ \text { 毛刺蟹科 } & \text { Pilumnidae } & \text { 团岛毛刺蟹 } & \text { Pilumnus tuantaoensis } \\ \text { 毛刺蟹科 } & \text { Pilumnidae } & \text { 裸盲蟹 } & \text { Typhlocarcinus nudus } \\ \text { 豆蟹科 } & \text { Pinnotheridae } & \text { 异足倒颚蟹 } & \text { Asthenognathus inaequipes } \\ \text { 豆蟹科 } & \text { Pinnotheridae } & \text { 豆形短眼蟹 } & \text { Xenophthalmus pinnotheroides }\end{array}$

腕足动物门 Brachiopoda

贯壳贝科 Terebratalidae 酸浆贯壳贝 $\quad$ Terebratalia coreanica

\section{棘皮动物门 Echinodermata}

\begin{tabular}{|c|c|c|c|}
\hline 海羊齿科 & Antedonidae & 锯羽丽海羊齿 & Antedon serrata \\
\hline 砂海星科 & Luidiidae & 砂海星 & Luidia quinaria \\
\hline 海盘车科 & Asteriidae & 多棘海盘车 & Asterias amurensis \\
\hline 阳遂足科 & Amphiuridae & 日本倍棘蛇尾 & Amphioplus japonicus \\
\hline 阳遂足科 & Amphiuridae & 光亮倍棘蛇尾 & Amphioplus lucidus \\
\hline 阳遂足科 & Amphiuridae & 中华倍棘蛇尾 & Amphioplus sinicus \\
\hline 阳遂足科 & Amphiuridae & 滩栖阳遂足 & Amphiura vadicola \\
\hline 辐蛇尾科 & Ophiactidae & 近辐蛇尾 & Ophiactis affinis \\
\hline 刺蛇尾科 & Ophiotrichidae & 马氏刺蛇尾 & Ophiothrix marenzelleri \\
\hline 真蛇尾科 & Ophiuridae & 金氏真蛇尾 & Ophiura kinbergi \\
\hline 刻肋海胆科 & Temnopleuridae & 哈氏刻肋海胆 & Temnopleurus hardwicki \\
\hline 刻肋海胆科 & Temnopleuridae & 细雕刻肋海胆 & Temnopleurus toreumaticus \\
\hline 硬瓜参科 & Sclerodactylidae & 丛足硬瓜参 & Sclerodactyla multipes \\
\hline 沙鸡子科 & Phyllophoridae & 陆氏花海参 & Anthochirus loui \\
\hline 尻参科 & Caudinidae & 海地瓜 & Acaudina molpadioides \\
\hline 尻参科 & Caudinidae & 海棒槌 & Paracaudina chilensis \\
\hline 针参科 & Synaptidae & 棘刺针参 & Protankyra bidentata \\
\hline \multicolumn{4}{|c|}{ 半索动物门 Hemichordata } \\
\hline 史氏柱头虫科 & Spengeliidae & 青岛橡头虫 & Glandiceps qingdaoensis \\
\hline \multicolumn{4}{|c|}{ 尾索动物门 Urochordata } \\
\hline 柄海鞘科 & Styelidae & 柄海鞘 & Styela clava \\
\hline \multicolumn{4}{|c|}{ 头索动物门 Cephalochordata } \\
\hline 文昌鱼科 & Branchiostomidae & 青岛文昌鱼 & Brachiostoma japonicum \\
\hline \multicolumn{4}{|c|}{ 脊椎动物门 Vertebrata } \\
\hline 锦鳚科 & Pholidae & 云䲁 & Enedrias nebulosus \\
\hline 玉筋鱼科 & Ammodytidae & 玉筋鱼 & Ammodytes peronatus \\
\hline 虾虎鱼科 & Gobiidae & 普氏细棘虾虎鱼 & Acentrogobius pflaumii \\
\hline 虾虎鱼科 & Gobiidae & 中华栉孔虾虎鱼 & Ctenotrypauchen chinensis \\
\hline 虾虎鱼科 & Gobiidae & 小头栉孔虾虎鱼 & Ctenotrypauchen microcephalus \\
\hline 虾虎鱼科 & Gobiidae & 红狼牙虾虎鱼 & Odontamblyopus lacepedii \\
\hline 虾虎鱼科 & Gobiidae & 纹缟虾虎鱼 & Tridentiger trigonocephalus \\
\hline
\end{tabular}

各类群按系统排序, 科下阶元按拉丁学名首字音序排列。 